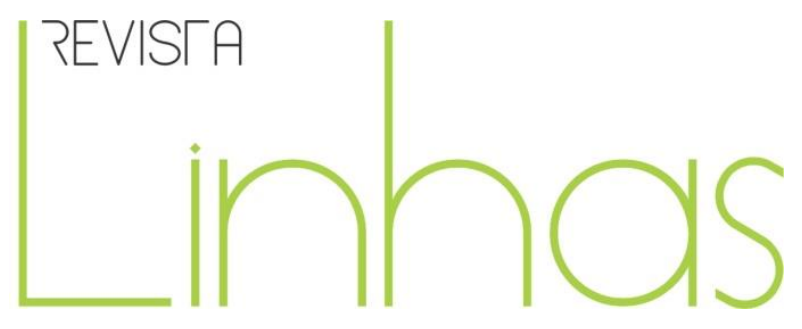

\title{
Filosofia da práxis na constituição da hegemonia da classe trabalhadora segundo Gramsci
}

\begin{abstract}
Resumo
Gramsci avança em relação à interpretação de Marx, que fundamenta suas reflexões sobre a exploração da classe dominada pela classe dominante. Em contribuição às análises de Marx, Gramsci desenvolve uma interpretação original, destacando o papel dos intelectuais orgânicos no processo revolucionário por meio da conquista da hegemonia. O presente artigo tem como objetivo, portanto, investigar as contribuições de Antonio Gramsci para a Educação. Trata-se de uma pesquisa bibliográfica, a qual buscou analisar alguns conceitos importantes para Gramsci, como a escola unitária. Como resultados, destaca-se que compete ao espaço escolar, por meio de intelectuais orgânicos, formar as futuras gerações e esclarecer os filhos da classe trabalhadora sobre os processos de dominação da classe burguesa, de forma a emancipá-los da dominação. Nessa perspectiva, este artigo demonstra, conforme Gramsci, o não aceite de uma escola para a classe trabalhadora e outra para a elite. É necessário que prevaleça a escola unitária, capaz de proporcionar à classe trabalhadora iguais oportunidades de realização e de apropriação do saber e da cultura.
\end{abstract}

Palavras-chave: Hegemonia. Práxis (Filosofia). Educação - Filosofia.
Fábio Antonio Gabriel

Universidade Estadual de Ponta

Grossa - UEPG - Ponta Grossa/PR Brasil

fabioantoniogabriel@gmail.com

Ana Lúcia Pereira

Universidade Estadual de Ponta Grossa - UEPG - Ponta Grossa/PR Brasil

ana.lucia.pereira.173@gmail.com

Tatiane Skeika Monteiro

Universidade Estadual de Ponta Grossa - UEPG - Ponta Grossa/PR Brasil

tati.skeika@gmail.com

\footnotetext{
Para citar este artigo:

GABRIEL, Fábio Antonio; PEREIRA, Ana Lúcia; MONTEIRO, Tatiane Skeika. Filosofia da práxis na constituição da hegemonia da classe trabalhadora segundo Gramsci. Revista Linhas. Florianópolis, v. 21, n. 46, p. 252-272, maio/ago. 2020.
} 


\title{
Philosophy of praxis in the constitution of hegemony of the working class according to Gramsci
}

\begin{abstract}
Gramsci advances in relation to the interpretation of Marx, who bases his reflections on the exploitation of the dominated class by the ruling class. In contribution to Marx's analysis, Gramsci develops an original interpretation, highlighting the role of the organic intellectuals in the revolutionary process through the conquest of hegemony. The present paper aims to investigate Antonio Gramsci's contributions to Education. It is a bibliographical research, which sought to analyze some important concepts for Gramsci, such as the unitary school. As a result, it is important to note that the school space is responsible, through organic intellectuals, for educating future generations and explain to the children of the working class about the domination processes of the bourgeoisie, in order to emancipate them from domination. In this perspective, this paper demonstrates, according to Gramsci, the nonacceptance of a school for the working class and another for the elite. It is necessary that the unitary school prevail, capable of providing the working class with equal opportunities for the realization and appropriation of knowledge and culture.
\end{abstract}

Keywords: Hegemony. Praxis (Philosophy). Education. Philosophy. 
Nascido em 1891, na Sardenha, membro de família pobre, Gramsci "[...] apresentou interesse e preocupação com as classes e povos em condições subalternas." (NASCIMENTO; SBARDELOTTO, 2008, p. 276). A sua produção bibliográfica de incorpora categorias marxianas, considerando-se os antagonismos presentes na relação entre classe trabalhadora e burguesa. Gramsci teve sua apreensão direcionada à intensa militância, sempre ligado às suas ideias marxistas, seara em que empreendeu uma luta intensa contra o Estado burguês liberal.

Gramsci (apud NOSELLA, 2008) chama sua filosofia de "filosofia da práxis", justamente por considerar a premissa de Marx de que tudo que os homens haviam pensado até aquela data deveria servir de norte para a execução prática no cotidiano das pessoas, a fim de promover a necessária transformação do mundo, de acordo com as ideias marxianas. Gramsci foi um intelectual engajado nas lutas da classe trabalhadora de sua época, participando ativamente do Partido Comunista da Itália. Justamente em razão de suas convicções e luta incansável, ele foi preso, o que não motivou qualquer arrefecimento de suas convicções, uma vez que nem mesmo a prisão logrou comprometer sua sede de luta, comprovada com a vasta produção filosófica sobre a vida social.

Cadernos do Cárcere $^{2}$ reúne sua produção filosófica, que adquire significativa relevância justamente por pensar em uma educação unitária que coloca em destaque, como imperiosa necessidade, a existência do intelectual orgânico na constituição de uma

\footnotetext{
${ }_{1}^{1}$ Agradecimentos: CAPES - FAG e TSM agradecem o apoio financeiro (bolsa de doutorado). FUNDAÇÃO ARAUCÁRIA - FAG e ALP agradecem o apoio financeiro (bolsa de doutorado e bolsa produtividade).

${ }^{2}$ São relevantes as informações de Semeraro (2006, p. 41, grifos do autor): "Em seu conjunto, se pode dizer que os escritos de Gramsci, particularmente os Cadernos, se apresentam como uma grande arena de confronto com as ideologias massificadoras do economismo, do fascismo e da burocracia, ao mesmo tempo em que esboçam um revolucionário projeto de sociedade fundado no autogoverno e na nova concepção de hegemonia a ser construído pelas classes subalternas como superação de todas as formas de imposição e de submissão. Em relação ao marxismo tradicional, que acentuava mais o poder da 'crítica' e apostava na revolução 'explosiva', a orientação fundamental que se nota nos Cadernos de Gramsci é no sentido da construção de uma nova 'práxis' coletiva dos grupos subalternos, na elaboração da filosofia da práxis e da concepção de uma revolução em todos os campos, de mais completa e longa duração". Ainda vale ressaltar o esclarecimento de Manacorda (2013, p. 131): "São cadernos de tamanho variado e de conteúdos diversos, que podem ser atribuídos a dois períodos distintos: ao primeiro período - entre 1929 e 1932 - nove cadernos de miscelâneas; ao segundo período - entre 1932 e 1935 - os outros vinte cadernos, que, à exceção de três que também tratam de miscelâneas, são todos 'especiais', isto é, dedicados normalmente a um único assunto, com base no último plano de trabalho, elaborado em 1932”.
} 
base de sustentação argumentativa na luta sem trégua pela conquista da hegemonia da classe trabalhadora (SEMERARO, 2006). Para Gramsci, é necessário criar uma nova cultura que esteja vinculada à filosofia da práxis:

\begin{abstract}
Criar uma nova cultura não significa apenas fazer individualmente descobertas "originais"; significa também e sobretudo difundir criticamente verdades já descobertas, "socializá-las", por assim dizer, transformá-las, portanto, em base de ações vitais, em elemento de coordenação e de ordem intelectual e moral. O fato de que uma multidão de homens seja conduzida a pensar, coerentemente e de maneira unitária, a realidade presente é um fato "filosófico" bem mais importante e "original" do que a descoberta, por parte de um "gênio" filosófico, de uma nova verdade que permaneça como patrimônio de pequenos grupos de intelectuais. (GRAMSCI apud NOSELLA, 2008, p. 62, grifos do autor)
\end{abstract}

Neste artigo, expomos, inicialmente, alguns conceitos da filosofia da práxis do autor de Cadernos do Cárcere; posteriormente, apresentamos um estudo sobre educação, segundo o mesmo filósofo; em seguida, discorremos sobre os intelectuais orgânicos em Gramsci, e finalizamos apontando a necessidade de repensarmos o modelo de formação humana que está sendo empreendido na sociedade atual.

\title{
Conceitos da filosofia da práxis em Gramsci
}

Para compreender Gramsci, é de fundamental importância resgatar as contribuições teóricas de Marx, sobretudo sua interpretação sobre o trabalho e sua divisão social; sua relevância na constituição do homem e da sociedade. Trata-se de compreender a teoria e o método desenvolvidos por Marx, ou melhor, o materialismo histórico e dialético e o lugar da educação nesse conjunto de interpretações e análises.

Gramsci preocupa-se, também, com a infraestrutura (a economia) e a superestrutura (o Estado, a escola, o sistema jurídico, etc.) social. No debate que envolve as contribuições do marxismo para a educação, e nas quais Gramsci tem lugar de destaque, a questão da reprodução e da transformação social também são relevantes. Jesus (2005, p. 45) afirma que Marx e Engels, apesar de não terem se debruçado com mais ênfase na educação, oferecem reflexões a respeito de questões educacionais que 
representam “[...] um profundo questionamento para a construção e para a consolidação de uma teoria escolar socialista." (JESUS, 2005, p. 46). A educação era, para Marx e Engels, uma arma particularmente relevante e fundamental para acabar com a divisão da situação social e econômica entre trabalhadores e intelectuais. Percebemos, em Gramsci, uma crítica ao saber enciclopédico, um tipo de saber não reflexivo que é transmitido de forma a não promover um questionamento.

É preciso perder o hábito e deixar de conceber a cultura como saber enciclopédico, no qual o homem é visto sob a forma de recipiente para encher e amontoar com dados empíricos, com fatos ao acaso e desconexos, que ele depois deverá arrumar no cérebro como nas colunas de um dicionário para poder então, em qualquer altura, responder aos vários estímulos do mundo externo. (GRAMSCI apud NOSELLA, 2008, p. 39)

Nesse sentido, a filosofia da práxis propõe um entendimento de uma filosofia que busca investigar as relações entre filosofia e vida, superando uma filosofia que seja enciclopédica no sentido de limitar-se a conhecimentos que não se relacionem em nada com a vida.

Em Marx, segundo Jesus (2005, p. 47), o conceito de "onilateralidade" relaciona-se à divisão do trabalho que propicia o surgimento de uma divisão de classes. Tal divisão do trabalho produziu unilateralidade porque o trabalho na sociedade capitalista aliena o trabalhador, expropria o que é devido a esse mesmo trabalhador, que, muitas vezes, se vê obrigado a realizar uma tarefa repetitiva e desumanizadora. No entanto, o que significa onilateralidade? Seu significado está relacionado ao "[...] desenvolvimento total, completo, multilateral, em todos os sentidos, das faculdades e das forças produtivas, das necessidades e das capacidades de sua satisfação." (JESUS, 2005, p. 47). Nessa perspectiva, “[...] 'onilateralidade' significa o desenvolvimento global do homem realizado sob as bases do trabalho como atividade vital e princípio da escola socialista." (JESUS, 2005, p. 47).

Foi na Instrução aos Delegados, do I Congresso da Associação Internacional dos Trabalhadores, ocorrido em Genebra, em 1866, que Marx, pela primeira vez, apresentou uma definição sobre o entendimento socialista de ensino. Ele teria afirmado, de acordo 
com sua percepção, que a educação compreende três coisas: “Primeira - educação mental; Segunda - educação física; Terceira - educação tecnológica, responsável pelos princípios gerais de todos os processos da produção, e que, por sua vez, inicia a criança e o jovem no manejo dos instrumentos elementares de todos os ofícios." (MARX, OE, II, 81 apud JESUS, 2005, p. 48).

Ainda é válido ressaltar que "[...] a biografia e a militância de Gramsci não deixam dúvidas quanto a sua íntima vinculação com o marxismo, cujas profundas convicções o levaram a fundar o Partido Comunista da Itália." (SEMERARO, 2006, p. 39). É pelo trabalho que o homem consegue superar as intempéries da vida e assim sobreviver. Para Nascimento e Sbardelotto:

[...] o homem se distingue dos animais pelo "trabalho". Sendo este trabalho comum a todos os seres humanos como forma de obter sua subsistência, para a teoria marxista é inadmissível a exploração de uma minoria sob o trabalho da maioria. Isso significa que, enquanto uns trabalham para produzir os bens de subsistência para todos, uma parcela da sociedade desfruta do ócio. [...]. O sistema capitalista, fundado no princípio da propriedade privada dos meios de produção, alimenta-se desta dicotomia entre capital e trabalho assalariado. Para Marx, o tipo de trabalho característico da sociedade capitalista é o trabalho assalariado. Nesta sociedade, existe a classe burguesa que detém a propriedade privada dos meios de produção e a classe trabalhadora que possui apenas como propriedade a sua força de trabalho. (NASCIMENTO; SBARDELOTTO, 2008, p. 277)

Desse modo, o sistema capitalista tem como fonte de seu fundamento a exploração que a classe burguesa promove sobre a classe proletária. O ponto focal dessa exploração é a mais-valia, que não significa exatamente lucro, mas, sim, a expropriação que a classe burguesa promove ao se apropriar dos resultados do trabalho do proletário. Dessa forma, possivelmente o proletário nunca conseguirá comprar aquilo que ele mesmo produz, porque é explorado pelo dono do meio de produção que se apropria dos frutos do trabalho que a classe proletária produz. Para que tal processo de exploração se perpetue, o explorador luta pela manutenção não apenas da hegemonia econômica, que se refere à detenção dos meios de produção (estrutura), como também da hegemonia cultural (superestrutura). 
Segundo Manacorda (2013, p. 29), Gramsci combate em duas frentes: “[...] a corrente reformista da cultura, aceita como herança a ser imposta às massas por obra e graça dos intelectuais", e a corrente extremista que prevê a rejeição da cultura “[...] em nome do fato revolucionário, dois termos opostos, mas complementares, que ele busca superar com uma ação e com uma cultura que seja ativa por força de sua organização" (MANACORDA, 2013, p. 29). Sobre os intelectuais e sua importância na sociedade e na maneira que eles se contrapõem ao processo de massificação, Gramsci, na antologia organizada por Nosella, afirma que:

\begin{abstract}
Os intelectuais se desenvolvem lentamente, muito mais lentamente do que qualquer outro grupo social, por causa de sua própria natureza e de sua função histórica. Eles representam toda a tradição cultural de um povo; querem resumir e sintetizar toda a história deste povo. $E$ isso vale sobretudo para o velho tipo de intelectual, aquele nascido no terreno camponês. Supor exequível que ele possa, enquanto massa, romper com todo o passado para se pôr completamente no terreno de uma nova ideologia é absurdo. É absurdo para os intelectuais enquanto massa; e talvez seja absurdo também para muitíssimos intelectuais tomados individualmente, apesar de todos os esforços honestos que eles fazem e querem fazer neste sentido. (GRAMSCI apud NOSELLA, 2008, p. 58)
\end{abstract}

As conquistas da classe dominada não devem se limitar "[...] às reivindicações econômicas, à produção e ao consumo material." (SEMERARO, 2006, p. 29), mas, sim, devem inaugurar uma nova fonte axiológica que permita o progresso intelectual da massa. É pela ideologia que determinados grupos sociais “[...] tomam consciência do próprio ser social, da própria força, das próprias responsabilidades, do próprio devir." (SEMERARO, 2006, p. 31). Em outras palavras, os burgueses não exercem seu domínio apenas ao apropriarem-se dos meios de produção, mas logram perpetuar a manutenção de tal forma de exploração justamente pela hegemonia cultural. É essa a força propulsora, ideológica, do status quo que a classe dominante detém. Mediante o processo de dominação ideológica, compete ao espaço escolar formar as futuras gerações, esclarecer os filhos da classe trabalhadora sobre os processos de dominação da classe burguesa e “[...] aprofundar 'a intelectualidade' de cada indivíduo, bem como multiplicar e aperfeiçoar as diversas especializações." (MANACORDA, 2013, p. 261, grifo do autor). Segundo Vieira: 
Gramsci pensa a questão da formação do indivíduo como uma função estratégica da política, como parte da implementação do projeto de uma classe na perspectiva de se fazer hegemônica, como tarefa de uma vanguarda sobre a militância, como responsabilidade dos mais velhos perante os mais jovens, na perspectiva de criar formas mais avançadas de civilidade. (VIEIRA, 1999, p. 64)

Marx inaugura uma nova filosofia, a práxis, que é também valorizada por Gramsci, que vê a necessidade de adotá-la como um exercício de reflexão para transformar a realidade. "A obra de Karl Marx é a base da metodologia utilizada por Gramsci." (LIMA, 2016, p. 171). "Práxis porque está diretamente envolvida com a realidade." (SEMERARO, 2006, p. 10) e também “[...] com o movimento real que supera o estado atual das coisas e com a transformação de seus próprios agentes em sujeitos políticos ativos, autônomos e associados" (SEMERARO, 2006, p. 10). Gramsci entende que a filosofia da práxis deve recriar-se constantemente. Desse modo, pode-se compreender a filosofia da práxis nos seguintes termos:

A filosofia da práxis, portanto, não é "ato puro", puro pensamento, esquema gnosiológico abstrato que "cria" idealisticamente, as coisas e os fatos, mas "ato impuro", atividade concreta, histórica, fundada em relações abertas, dinâmicas, dialéticas do homem com a natureza, da vontade humana com as estruturas econômicas, dos projetos políticos com as cristalizações culturais. E embora em Gramsci se encontrem elementos que tendem a reduzir a natureza a correlato passivo da práxis humana transformadora, não há uma diminuição da realidade objetiva e de sua independência ontológica, mas há uma ênfase no sentido de que a natureza, a matéria, o objeto são significados pela atividade humana. Diversamente, não se explicaria o embate crítico que travou com o neoidealismo italiano e o criacionismo gnosiológico de Croce e Gentile. (SEMERARO, 2006, p. 34, grifos do autor)

A proposta de Gramsci para a escola socialista é encontrada, principalmente, no Caderno 12 do Cadernos do Cárcere. Coutinho (2014, p. 86) afirma que o Caderno 12 foi iniciado e concluído em 1932, e tem, como conteúdo, notas sobre os intelectuais e sobre o princípio educativo. Trata-se inicialmente de uma proposta para a Itália, mas que poderia expandir-se pelo mundo. "Gramsci entende que, no modo de produção capitalista, a escola não deveria ser imediatamente interessada, oposta àquela aristocrática, considerada, por ele, como interessada, por servir a uma minoria de privilegiados, por 
destinação da família." (JESUS, 2005, p. 57). O filósofo em referência defende que a classe trabalhadora precisa de uma escola desinteressada, “[...] uma escola que ofereça à criança a possibilidade de se formar, de se tornar homem, de adquirir critérios gerais indispensáveis para o desenvolvimento do caráter." (JESUS, 2005, p. 58). Gramsci também reconhece que essa escola desinteressada encontra dificuldades para se concretizar, porque o sistema capitalista procura assegurar privilégios aos burgueses e pensa em uma escola de categoria inferior para a classe dominada. Nas palavras dele:

\begin{abstract}
A tendência atual é a de abolir qualquer tipo de escola "desinteressada" (não imediatamente interessada) e "formativa", ou de conservar apenas um seu reduzido exemplar, destinado a uma pequena elite de senhores e de mulheres que não devem pensar em preparar-se para um futuro profissional, bem como a de difundir cada vez mais as escolas profissionais especializadas, nos quais o destino do aluno e sua futura atividade são predeterminados. A crise terá uma solução que, racionalmente, deve seguir esta linha: escola única inicial de cultura geral, humanista, formativa, que equilibre de modo justo o desenvolvimento da capacidade de trabalhar manualmente (tecnicamente, industrialmente) e o desenvolvimento das capacidades de trabalho intelectual. Deste tipo de escola única, através de repetidas experiências de orientação profissional, passar-se-á a uma das escolas especializadas ou de trabalho produtivo. (GRAMSCl, 2004, p. 34)
\end{abstract}

Assim, é necessário pensar na relevância de uma escola unitária que não tenha como finalidade primeira apenas preparar pessoas para o mercado de trabalho. É necessário possibilitar que a classe trabalhadora também tenha acesso a uma educação desinteressada e que proporcione a esses mesmos trabalhadores condições igualitárias de realização pessoal e profissional. Assim, aprofundamos, na próxima seção, o entendimento sobre a educação em Gramsci, procurando compreender o contexto em que ele está inserido. É possível perceber, entretanto, como o pensamento desse autor pode ser utilizado para entender a realidade atual.

\title{
Educação em Gramsci
}

Na Itália de Gramsci, a classe trabalhadora tinha acesso apenas à escola primária. Era muito difícil o ingresso à escola média pela redução dos institutos médios; a escola clássica e a entrada às universidades eram privilégios apenas da elite. "A elitização da 
Reforma Gentille teve efeito imediato porque os trabalhadores tiveram que se contentar com a escola elementar e, no máximo, com a 'profissional'." (JESUS, 2005, p. 65, grifo do autor). O autoritarismo didático fazia parte da caracterização das reformas governamentais da educação, inclusive a de Gentille. A escola italiana, no tempo de Gramsci, sofria influência de várias correntes filosófico-pedagógicas como, por exemplo, o positivismo, que é uma doutrina filosófica defendida por Augusto Comte e difundida pelos seus seguidores que afirmavam que a humanidade teria passado por três estágios, a saber: o teológico, o metafísico e finalmente, o positivo. O estágio teológico era caracterizado por uma explicação dos fenômenos ocorridos no mundo, partindo da causalidade divina; o estágio metafísico, pela explicação filosófica do mundo, ainda sem uma comprovação científica; finalmente, o estágio positivo, formal, em que prevalece uma explicação científica dos fenômenos observados em laboratório.

No seio dessa influência idealista, surge o fascismo que, de modo ditatorial, impôsse como sistema político, em uma perspectiva de conceito absolutista de Estado. Mussolini confere a Gentile a missão de executar reformas para a escola, que redundaram em discriminação e na opressão social. É nesse contexto que Gramsci pensa na relevância da escola unitária. Para Jesus, essa escola se caracterizava da seguinte forma:

A natureza da escola única foi explicada, em grandes linhas, por Gramsci, como "uma escola inicial de cultura geral, humanista, formativa, que equilibrasse equanimemente o desenvolvimento da capacidade de se trabalhar manualmente e o desenvolvimento do trabalho intelectual". E para precisar o conteúdo daquela escola, Gramsci fez comparações com a escola humanística, cujos méritos históricos reconheceu, aprovou seus ideais de formação humana, enquanto atacou a escola burguesa como inútil, porque inadequada para servir aos novos tempos que se caracterizavam pelo "trabalho industrial moderno". (JESUS, 2005, p. 67, grifos do autor)

Nascimento e Sbardelotto (2008, p. 280) afirmam que, no final do século XIX, no contexto da Europa, ocorreu um aumento dos debates sobre a obrigação do Estado em promover condições favoráveis para uma educação pública generalizada. Instalou-se um debate a respeito do paradoxo que se exercia ao se oferecer um ensino de formação humanista, científica, para a classe burguesa, enquanto a classe trabalhadora deveria 
submeter-se a um ensino de formação técnica, destinada ao trabalho, e nesse antagonismo de classes se perpetuava o sistema capitalista. Em Gramsci, é perceptível uma crítica à divisão da escola pública, sendo uma destinada à classe operária e outra, à elite burguesa. Para a classe operária, havia o referido programa de educação técnica destinada à formação de mão de obra, de trabalho, e outro ensino de formação humanística destinado à burguesia. Nesse sentido, em relação ao ensino educacional italiano, Nascimento e Sbardelotto apontam:

Assim, a preocupação de Gramsci com a educação tinha relação com a sua crítica ao ensino técnico italiano de caráter pragmático, destinado aos trabalhadores - e estes destinados ao trabalho assalariado, a submissão e exploração pelo capital - e o ensino humanista italiano, oferecido à burguesia - esta sim destinada a comandar, a dominar, a governar a sociedade capitalista, compondo os cargos na administração pública do Estado liberal-burguês. O processo de trabalho para Gramsci deve ser o princípio educativo, mas não o modelo de escola profissional de sua época que apenas cumpria a função de eternizar às estratificações de classes e predestinação da maioria ao trabalho alienante, sob falsos princípios democráticos. (NASCIMENTO; SBARDELOTTO, 2008, p. 281)

Gramsci, segundo Nascimento e Sbardelotto (2008, p. 282), entende que, para a efetivação de uma escola unitária, com acesso de todos a uma educação formativa e cultural ampla e não apenas profissional, se impunham medidas capazes de reduzir o número de alunos por turma, a criação de bibliotecas especializadas, além de salas para trabalhos em laboratórios e refeitórios.

Na perspectiva de Gramsci, interligam-se o discurso sobre os intelectuais, sobre a cultura e sobre o princípio educativo da classe trabalhadora. "A educação em Gramsci é eminentemente política, assim como a política passa a ser vista como comportando uma dimensão educativa." (MARTINS, 2013, p. 27). É necessária a construção de uma análise da condição da real situação da classe trabalhadora para que a escola não atue como reprodutora da hegemonia burguesa que, conforme já exposto, não é apenas econômica, mas também, e sobretudo, cultural. Segundo Nascimento e Sbardelotto (2008):

[...] para Gramsci a "escola unitária" constitui-se numa proposta educacional voltada para a emancipação da classe trabalhadora. $\mathrm{O}$ 
compromisso político de Gramsci para com a superação da sociedade capitalista e implementação de um novo modelo de sociedade, fica claro a partir da sua concepção do processo de trabalho. Embora não defenda que uma educação "desinteressada" deva aguardar a superação da sociedade capitalista, a condição para sua efetiva implementação está condicionada à superação desse modelo de sociedade que sobrevive à custa da exploração do trabalho. (NASCIMENTO; SBARDELOTTO, 2008, p. 289, grifos das autoras)

Segundo Manacorda (2013, p. 178), Gramsci opta por uma escola unitária de cultura geral humanística e busca estudar os modos concretos da forma como se efetivaria essa proposta de educação escolar. Gramsci considera que seria necessário aumentar os investimentos em educação pública no seu tempo. Sobre a organização escolar na perspectiva de Gramsci, Manacorda (2013) afirma:

O liceu, a escola na qual os jovens ingressam "imediatamente após a crise da puberdade", deve ser considerado como a fase transitória mais importante para a formação daquela autodisciplina intelectual e daquela autonomia moral que são os "valores fundamentais do humanismo", em vista da posterior especialização seja intelectual, na universidade, seja profissional. Não se creia que Gramsci se prenda aqui a uma concepção tradicional do humanismo; recorde-se como, ao invés disso nele, os valores da disciplina intelectual e moral, que se opõem ao autodidatismo e à licenciosidade, estão identificados com a concepção de cultura e de um modo de vida modernos, ligados aos novos sistemas de produção, e como isso se conecta à ideia de uma atividade prática embebida de caráter científico e de uma ciência capaz de produzir etc. É no liceu que deve começar o estudo do método científico, um estudo criativo e não somente receptivo. (MANACORDA, 2013, p. 182, grifos do autor)

Para que ocorra a revolução socialista, é necessária uma mudança de mentalidade, sobretudo da classe dominada. Tal transformação deve ocorrer por meio da escola, com a participação e a formação de intelectuais que representem a ideologia proletária, gerados no âmago da classe trabalhadora e comprometidos com a emancipação e a revolução social. Trata-se de uma escola que não faz distinção entre os filhos da classe burguesa e os filhos da classe proletária e que permita aos intelectuais orgânicos se apropriarem dos conhecimentos necessários à sua luta revolucionária. “A escola é o instrumento para elaborar os intelectuais de diversos níveis. A complexidade da função intelectual nos vários Estados pode ser objetivamente medida pela quantidade das escolas 
especializadas." (GRAMSCI, 2004, p. 19). Em relação à necessidade de uma escola que viesse ao encontro das necessidades do proletariado, Gramsci, na antologia organizada por Nosella (2008), aponta que:

\begin{abstract}
O proletariado precisa de uma escola desinteressada. Uma escola na qual seja dada à criança a possibilidade de ter uma formação, de tornar-se homem, de adquirir aqueles critérios gerais que servem para o desenvolvimento do caráter. Em suma, uma escola humanista, tal como a entendiam os antigos e, mais recentemente, os homens do Renascimento. Uma escola que não hipoteque o futuro da criança e não constrinja sua vontade, sua inteligência, sua consciência em formação a mover-se por um caminho cuja meta seja prefixada. Uma escola de liberdade e de livre iniciativa, não uma escola de escravidão e de orientação mecânica. Também os filhos do proletariado devem ter diante de si todas as possibilidades, todos os terrenos livres para poder realizar sua própria individualidade do melhor modo possível e, por isso, do modo mais produtivo para eles mesmos e para a coletividade. (GRAMSCI apud NOSELLA, 2008, p. 48)
\end{abstract}

O ápice da formação humana processa-se, segundo Gramsci, no âmbito da universidade. Nos últimos textos apresentados, em que trabalha com o conceito de processo escolar unitário, Gramsci considera a relevância do acesso da classe trabalhadora ao âmbito universitário. Nesse sentido, é interessante ressaltar que ele critica a universidade que apresenta para os acadêmicos um saber totalmente enciclopédico e indiscutível. $\mathrm{O}$ autor entende que a universidade deve ser o espaço para o pensamento, para o exercício e para a experiência conceitual, ou seja, deve-se permitir que os acadêmicos possam continuamente exercitar a experiência do debate de conteúdos produzidos pela academia. "A universidade se apresenta para Gramsci como uma 'escola' de alta cultura, de elaboração crítica e científica, imprescindível a qualquer hegemonia." (JESUS, 2005, p. 75, grifo do autor). É importante ainda ressaltar que "[...] o trabalho dos intelectuais só será producente se as filosofias que formularam se disseminarem a tal ponto de se tornarem vontade, transformarem-se em uma força social que opere objetivamente na história, isto é, em ideologia.” (MARTINS, 2013, p. 22).

Para Gramsci (2004), a escola constitui-se como uma instituição destinada, por missão histórica, a preparar pessoas que se configurem como os novos intelectuais para a sociedade socialista. As circunstâncias históricas em que viveu esse filósofo o levaram a 
compreender que a cultura era uma necessidade para possibilitar o surgimento da hegemonia da classe trabalhadora. É necessário, para ele, empreender buscas que possibilitem a transição para uma nova perspectiva escolar capaz de formar cidadãos que atuem na realidade social em que se inserem.

Para pensar-se a educação a partir de Gramsci, faz-se necessário uma reflexão sobre o conceito “hegemonia”. Alves (2010) apresenta-nos que é Gramsci que elabora, de forma mais minuciosa, o conceito de hegemonia. Ele percebe que, quando um grupo social mantém uma situação de subordinação em relação a outro grupo, é muito comum que o subordinado absorva a visão de mundo daquele que o domina. Assim, é preciso que os dominados resistam ideologicamente aos ditames ideológicos daqueles que os dominam. Mais do que querer dominar pela força, é possível dominar pelas ideias. Contudo, a hegemonia é ético-política e é, também, econômica. Alves (2010, p. 79) entende que "[...] se as classes subalternas pretendem criar um novo bloco histórico, devem desenvolver seu próprio aparato hegemônico."

A educação é uma das possibilidades de construir uma hegemonia da classe trabalhadora por meio do processo educativo. Contudo, enquanto a classe trabalhadora não se organiza para lutar por uma escola unitária, o que ocorre é a constituição de uma escola para os dominantes em que os dominados precisam se adaptar.

\section{Reformas Educacionais no Brasil e a análise a partir de Gramsci}

Pensar no papel da filosofia da práxis e da educação em Gramsci remete-nos a refletir sobre as atuais reformas educacionais em curso no Brasil e sobre os rumos que a educação brasileira pode tomar. Nos últimos anos, o país tem enfrentado uma grande crise política e financeira, que acabou inclusive culminando no Impeachment da ex-presidente do Brasil. Essa crise tem se agravado cada vez mais, atingindo o campo cultural e social que tem se alastrado principalmente pelas mídias sociais. A exemplo disso, podemos citar o atual cenário político brasileiro que tem mostrado o quanto a educação faz falta na formação do homem, para que a história não se repita.

A onda de violência cibernética cresceu tanto que é natural vermos muitas pessoas defendendo candidatos fascistas, ignorando totalmente a história, revelando um aspecto 
triste do atual cenário da educação brasileira: muitas pessoas passam pela escola, mas a escola infelizmente não passa por elas. O resultado de todo esse processo pode ser caótico, pois há pessoas que se dizem "cidadãos de bem”, flertando com o fascismo, e isso denota uma verdadeira afronta a toda a sociedade e à democracia no país.

Esse momento tem sido histórico também para a educação brasileira, que vem sofrendo duros golpes e ataques principalmente por meio de projetos de leis e medidas provisórias que têm afetado diretamente a estrutura curricular e política da Educação nacional. No meio desse contexto político atual, existe uma grande parcela de representantes políticos que defendem o projeto de lei Escola sem partido e/ou a questão da ideologia de gênero, que tem sido deturpada nas mídias sociais, ameaçando não somente a autonomia das escolas e dos professores, mas também o respeito ao outro.

Atrelados a todos esses acontecimentos destacamos, ainda, como golpes sofridos pela educação, a Medida Provisória (MP) $n^{\circ}$ 746/16, que foi aprovada pelo Senado e sancionada pelo Executivo Federal em 2017, reformulando o Ensino Médio no Brasil e alterando artigos da LDBEN nº 9.394/1996 (BRASIL, 2016). Desde o retorno das disciplinas de Filosofia e de Sociologia como obrigatórias em todos os anos do Ensino Médio, por meio da Lei $n^{\circ}$ 11.684, de 2008 (BRASIL, 2008), alterando o Art. 36 da LDB (Lei $n^{\circ}$ 9.394/96), tem ocorrido vários debates e gerado muitas críticas, porque, para muitos, a lei foi implementada "de forma apressada e sem o cuidadoso debate", conforme destacado pela Confederação Nacional dos Trabalhadores em Educação (CNTE, 2017).

Segundo Lino (2017), a reforma do Ensino Médio imposta pela Lei n 13.415/2017 determina uma configuração curricular que descaracteriza totalmente essa etapa da Educação Básica, principalmente como educação pública de qualidade. Para a autora, esse processo de reforma deu-se de forma autoritária e "avesso ao diálogo com a sociedade", configurando-se como "um retrocesso na política educacional." (LINO, 2017, p. 75). Nesse sentido, a Confederação Nacional dos Trabalhadores em Educação (CNTE) considera a reforma do Ensino Médio no Brasil como "[...] um conjunto mais amplo de medidas neoliberais e conservadoras" (CNTE, 2017, p. 337).

Parece-nos que há um grande interesse que essas disciplinas não permaneçam como área de conhecimento na formação básica dos nossos jovens e denotam uma clara afronta não somente à educação, mas também à democracia e à sociedade brasileira, 
pois demonstra-se, com isso, que grande parte dos nossos políticos eleitos não desejam que o povo tenha uma educação para cidadania, em que possam exercer os seus direitos, sua autonomia e, acima de tudo, que seja um ser pensante.

Somado a todo esse cenário, ainda tivemos a organização e a implantação da nova Base Nacional Curricular Comum (BNCC), que também foi caracterizada como um momento de grandes debates e críticas, pois, apesar das instâncias governamentais afirmarem que a Base Nacional Comum Curricular (BNCC) tenha se consolidado "[...] como fruto de um amplo processo de debate e negociação com diferentes atores do campo educacional e com a sociedade brasileira em geral." (BRASIL, 2017, p. 5), ela tem sofrido uma grande pressão por parte dos movimentos contrários à reforma curricular no Brasil.

Para Macedo (2016), a grande questão é: Por que aqueles que sabem as respostas para essas questões não foram e não são ouvidos? A autora posiciona-se contrária à construção das bases nacionais curriculares comuns, por conta dos aspectos de "prescrição" e "controle". Ela enfatiza que:

É uma aposta que constitui, sem dúvida, um desafio mais difícil do que produzir uma lista (de conteúdos ou de capacidades de fazer) que sirva de base comum nacional. Ela envolve formar bem os professores, e, principalmente, dar-lhes condições de trabalho e salário compatíveis, investir nas escolas e no trabalho lá realizado, enfim, valorizar a educação, e não o controle que a destrói como empreitada intersubjetiva. (MACEDO, 2016, p. 63)

A BNCC estava prevista para a organização do Ensino Fundamental e Médio, buscando atender aos desafios de formação pessoal, profissional e cidadã, bem como apresentar ações estratégicas para todos os educadores e gestores de educação do Brasil. Entretanto, não podemos deixar de destacar aqui que o Ministério da Educação apresentou a terceira e a última versão da Base Nacional Comum Curricular (BNCC) para o Ensino Infantil e Fundamental, e acabou deixando de fora do documento o Ensino Médio. Segundo Dantas (2018, p. 110), com essa atitude, “[...] dissociam-se os alicerces da Educação Básica, pois o Ensino Médio terá uma versão à parte. Vai ficando nítida uma formação simplificada/aligeirada para os/as filhos/as da classe trabalhadora." O autor destaca ainda que essa "[...] versão contraria as potencialidades de um país como o 
Brasil, dada a sua riqueza e diversidade cultural, geográfica e étnica, sendo subserviente aos ditames dos organismos multilaterais. Há, de fato, uma indesejável homogeneização cultural." (DANTAS, 2018, p. 109).

$\mathrm{Na}$ atual conjuntura política nacional, a proposta da nova Base Nacional Curricular corrobora a ideia de um projeto antidemocrático, que vai contra as lutas de classe, pois não abarca as necessidades que o povo precisa como educação de fato. Privilegia-se somente o interesse do Estado, da burguesia, caracterizando-se como um movimento de retrocesso na longa trajetória de conservadorismo que tanto marca a história do Brasil.

Entender como tem sido o movimento relacionado à educação e ao currículo é, portanto, de suma importância, principalmente quando analisamos o papel do currículo na construção da sociedade. Trata-se de um processo histórico como um movimento contínuo, mas caracterizado por muitas lacunas deixadas na educação, e com "grandes descontinuidades e rupturas" como destaca Tadeu da Silva (2013, p. 7).

Em tempos de prescrições oficiais que buscam impor e implementar um modelo único de currículo para todas as escolas brasileiras, pautado nas perspectivas tradicionais de currículo "[...] como uma atividade meramente técnica e administrativa" (TADEU DA SILVA, 2013, p. 37), baseada no modelo de racionalidade instrumental, conteudista e empresarial, podemos enfatizar a importância da escola na desarticulação da ideologia dominante conforme destacado por Gramsci. "Situando-se no próprio terreno da hegemonia como síntese teórico-prática do movimento revolucionário de transformação social que exige organicidade, seja do pensamento filosófico, seja da solidez organizativa e de centralização cultural." (OLIVEIRA, 2012, p. 3793).

É preciso, desse modo, força e organização para sobreviver aos desmontes dos governos neoliberais que ocupam hoje o poder no Brasil. Para isso, podemos trazer para esse debate o conceito de hegemonia a partir de Gramsci. Conforme destacamos anteriormente, acreditamos que a educação é uma das possibilidades, ou melhor é a principal via para se construir uma hegemonia da classe trabalhadora por meio do processo e do ato educativo, pois, como destaca Freire (2000), a educação é um ato político e não somos apenas sujeitos da história, mas também ajudamos a construí-la. 
Assim como destaca Gramsci, é preciso ter coragem e romper com o estado de subordinação, para que se possa ver a vida além da visão daquele que domina. Para isso, faz-se necessário que os dominados resistam ideologicamente aos ditames daqueles que dominam, e tenham forças para desenvolver "seu próprio aparato hegemônico", conforme destacado por Alves (2010).

A ideia de hegemonia de Gramsci vale também para pensarmos o nosso papel político, de educadores, principalmente nesse momento sombrio brasileiro que estamos atravessando, cujas disputas discursivas e ideias amplificadas nas mídias sociais promovem o discurso do ódio, da raiva, e, acima de tudo, o da manipulação e do preconceito. Portanto, o nosso discurso e a nossa intervenção podem fazer a diferença neste tempo de escuridão.

Precisamos continuar lutando por um currículo e uma BNCC que objetivem a construção de uma sociedade mais justa, solidária e, acima de tudo, mais humanizada, em que todos(as) possam ser vistos como seres humanos. É necessário, ainda, conscientizar os nossos alunos e a classe trabalhadora de que é imprescindível lutarmos por uma escola unitária, na qual não haja divisão entre ricos e pobres, dominantes e dominados, mas uma escola que promova a igualdade social em que todos possam ocupar os seus lugares, não se adaptando a eles, mas sendo capaz de formar cidadãos que possam atuar na realidade social em que se inserem como destacado por Gramsci.

\section{Considerações finais}

É possível verificar, a partir dos estudos de Gramsci, a relevância atribuída à escola unitária como uma oposição ao sistema educacional vigente em sua época. Tal sistema propunha uma separação entre os filhos de classe burguesa e os da classe trabalhadora. Aqueles teriam uma formação cultural ampla e abrangente, enquanto estes teriam apenas uma formação voltada ao mercado de trabalho. Urge, nesse contexto, a luta por uma escola unitária cujo currículo seja comum para todas as classes sociais.

A filosofia de Gramsci é intitulada de filosofia da práxis, justamente por se alinhar à premissa de Marx de que é necessário transformar a realidade. Conceito relevante para Gramsci é a "omnilateralidade", o qual representa a necessidade do desenvolvimento 
global do ser humano. Outra temática que é importante para o filósofo consiste em suas afirmações sobre o importante papel dos intelectuais na sociedade. É pelo exercício intelectual que se efetiva a organização de uma determinada ideologia e se constrói uma hegemonia.

Para que ocorra a revolução socialista, é necessária uma mudança na visão de mundo e, por isso, a escola exerce particular importância, porque é essa instituição que prepara os diversos intelectuais. Existem os intelectuais tradicionais que laboram na manutenção do status quo da classe dominante e os intelectuais orgânicos, cuja função é sistematizar uma ideologia da revolução que possibilite aos dominados emancipar-se da dominação.

Analisar o cenário brasileiro a partir de Gramsci permite-nos apontar que, por mais golpes que a educação e o povo brasileiro tenham sofrido nos últimos tempos, o espaço escolar ainda é a única possibilidade para a mudança, por meio de intelectuais orgânicos que o constituem. Só assim poderemos formar as futuras gerações e esclarecer os filhos da classe trabalhadora sobre os processos de dominação da classe burguesa, de forma a emancipá-los da dominação, e torná-los uma sociedade organizada, para que tenham condição de ocupar os seus espaços sociais. Nessa perspectiva, este artigo demonstra, conforme Gramsci, que é inaceitável uma escola para a classe trabalhadora e outra para a elite, se “todos são iguais perante a lei”. É necessário que prevaleça a escola unitária, capaz de proporcionar à classe trabalhadora iguais oportunidades de realização e de apropriação do saber e da cultura. Isso leva à reflexão de que, assim como nos tempos de Gramsci, os intelectuais orgânicos ainda possuem um importante papel no processo de construção de uma nova hegemonia, de forma a desempenhar a práxis revolucionária.

\section{Referências}

ALVES, Ana Rodrigues Cavalcanti. O conceito de hegemonia: de Gramsci a Laclau e Mouffe. Lua Nova, São Paulo, n. 80, p. 71-96, 2010. 
BRASIL. Lei $n^{\circ}$ 11.684, de 2 de junho de 2008. Altera o art. 36 da Lei $n^{\circ} 9.394$, de 20 de dezembro de 1996, que estabelece as diretrizes e bases da educação nacional, para incluir a Filosofia e a Sociologia como disciplinas obrigatórias nos currículos do ensino médio. Diário Oficial [da] República Federativa do Brasil: Seção 1, Brasília, DF, n.104, p. 1-2, 3 jun. 2008.

BRASIL. Medida Provisória No - 746, de 22 de setembro de 2016. Institui a Política de Fomento à Implementação de Escolas de Ensino Médio em Tempo Integral, altera a Lei ${ }^{\circ}$ 9.394, de 20 de dezembro de 1996, que estabelece as diretrizes e bases da educação nacional, e a Lei $n^{\circ} 11.494$ de 20 de junho 2007, que regulamenta o Fundo de Manutenção e Desenvolvimento da Educação Básica e de Valorização dos Profissionais da Educação, e dá outras providências. Diário Oficial [da] República Federativa do Brasil: Seção 1, Edição Extra, Brasília, DF, n. 184-A, p. 1-2, 23 set. 2016.

BRASIL. Ministério da Educação. Base nacional comum curricular - educação é a base: estudo comparativo entre a versão 2 a versão final. [Brasília: MEC], 2017. Disponível em: http://cnebncc.mec.gov.br/docs/BNCC_Estudo_Comparativo.pdf. Acesso em: 18 ago. 2018.

CNTE. Confederação Nacional dos Trabalhadores em Educação. A reforma do ensino médio suprime direitos, privatiza a educação e terceiriza os/as trabalhadores/as escolares. Revista Retratos da Escola, Brasília, v. 11, n. 20, p. 337-343, jan./jun. 2017.

COUTINHO, Carlos Nelson. De Rousseau a Gramsci: ensaios de teoria política. São Paulo: Boitempo, 2014.

DANTAS, Jéferson Silveira. O ensino médio em disputa e as implicações da BNCC para a área das Ciências Humanas. Universidade e Sociedade, Brasília, n. 61, p. 106-115, jan. 2018.

FREIRE, Paulo. Pedagogia da autonomia: saberes necessários à prática educativa. 15. ed. Rio de Janeiro: Paz e Terra, 2000.

GRAMSCI, Antonio. Apontamentos e notas dispersas para um grupo de ensaios sobre a história dos intelectuais. In: GRAMSCI, Antonio. Cadernos do cárcere. 3. ed. Rio de Janeiro: Civilização brasileira, 2004. p. 15-53.

JESUS, Antonio Tavares de. O pensamento e a prática escolar de Gramsci. Campinas: Autores Associados, 2005.

LIMA, Michelle Fernandes. A pesquisa no campo das políticas educacionais: contribuições de Antonio Gramsci. In: SCHLESENER, Anita Helena et al. (orgs.). Marximo(s) e educação. Ponta Grossa: UEPG, 2016. p. 163-177.

LINO, Lucilia Augusta. As ameaças da reforma desqualificação e exclusão. Revista

Retratos da Escola, Brasília, v. 11, n. 20, p. 75-90, jan./jun. 2017. 
MACEDO, Elizabeth. Base nacional curricular comum: a falsa oposição entre conhecimento para fazer algo e conhecimento em si. Educação em Revista, Belo Horizonte, v. 32, n. 2, p. 45-67, abr./jun. 2016.

MANACORDA, Mario Alighiero. O princípio educativo em Gramsci. Campinas: Alínea, 2013.

MARTINS, Marcos Francisco. Gramsci, filosofia e educação. Práxis Educativa, Ponta Grossa, v. 8, n. 1, p. 13-40, jan./jun. 2013.

NASCIMENTO, Maria Isabel Moura; SBARDELOTTO, Denise Kloeckner. A escola unitária: educação e trabalho em Gramsci. Revista HISTEDBR, Campinas, n. 30, p. 275-291, jun. 2008.

NOSELLA, Paolo (org.). Antonio Gramsci para os educadores. São Paulo; São Carlos: UNINOVE; UFSCAR, 2008.

OLIVEIRA, Thiago Chagas. Considerações acerca da influência de Gramsci no campo pedagógico brasileiro. SEMINÁRIO NACIONAL DE ESTUDOS E PESQUISAS "HISTÓRIA, SOCIEDADE E EDUCAÇÃO NO BRASIL”, 9, 2012, João Pessoa. Anais Eletrônicos [...]. João Pessoa: Universidade Federal da Paraíba, 2012. Disponível em:

http://www.histedbr.fe.unicamp.br/acer_histedbr/seminario/seminariog/PDFs/6.06.pdf. Acesso em: 2 set. 2018.

SEMERARO, Giovanni. Gramsci e os novos embates da Filosofia da práxis. Aparecida: Ideias \& Letras, 2006.

TADEU DA SILVA, Tomaz. Apresentação. In: GOODSON, F. Ivor. Currículo: teoria e história. Petrópolis: Vozes, 2013. p. 7-13.

VIEIRA, Carlos Eduardo. Cultura e formação humana no pensamento de Antonio Gramsci. Educação e Pesquisa, São Paulo, v. 25, n. 1, p. 51-66, jan./jun. 1999.

Recebido em: 27/06/2018 Revisões requeridas: $20 / 08 / 2018$

Aprovado em: 05/02/2019

Universidade do Estado de Santa Catarina - UDESC Programa de Pós-Graduação em Educação - PPGE

Revista Linhas

Volume 21 - Número 46 - Ano 2020 revistalinhas@gmail.com 